\section{International Scientific Journal Theoretical \& Applied Science}

p-ISSN: 2308-4944 (print) e-ISSN: 2409-0085 (online)

Year: $2016 \quad$ Issue: 12 Volume: 44

Published: 26.12.2016 http://T-Science.org
Denis Chemezov

Master of Engineering and Technology, Corresponding Member of International Academy of Theoretical and Applied Sciences, Lecturer of Vladimir Industrial College, Russian Federation chemezov-da@yandex.ru

SECTION 2. Applied mathematics. Mathematical modeling.

\title{
THE CHARACTER OF THE FLUID FLOW IN THE PIPELINES WITH THE LOCAL HYDRAULIC RESISTANCES
}

Abstract: The article are presented the results of a computer calculation of the change magnitude of pressure and velocity of the fluid flow at the room temperature before and after the sections of the sudden and the gradual expansions and contractions of the pipeline.

Key words: a fluid flow, an expansion, a contraction, a pressure, a channel, a length.

Language: English

Citation: Chemezov D (2016) THE CHARACTER OF THE FLUID FLOW IN THE PIPELINES WITH THE LOCAL HYDRAULIC RESISTANCES. ISJ Theoretical \& Applied Science, 12 (44): 62-68.

Soi: http://s-o-i.org/1.1/TAS-12-44-13 Doi: crossef http://dx.doi.org/10.15863/TAS.2016.12.44.13

\section{Introduction}

The flow in the pipeline is accompanied by the gradual loss of the hydraulic fluid pressure on the length. The hydraulic losses are occurred due to the viscous friction of the moving fluid at the different sections of the pipeline. Significant losses of the specific energy occur during the fluid flow on the sections of local hydraulic resistances. To the local hydraulic resistances are included: a sudden or a gradual expansion and contraction of the channel [1], a turn (elbow) $[2 ; 3 ; 4]$, a valve and the other not direct with the variable cross section of short pipeline sections in which a change of the velocities of fluid flow in the magnitude and direction is occurred.

The fluid flow in the conditions of the sudden or gradual change of cross section of the pipeline has virtually the same transitional character $[5 ; 6]$. Formation of the expanding or narrowing jets and the vortex fluid flows on the calculated length of the pipeline are observed. Vortex flows are reduced with the increasing diameter of the fluid jet. The developed vortex flows of fluid are observed on $2 / 3$ of the length of the conical sections of the pipeline.

The degree of the hydraulic losses in the pipelines with the local resistances is determined by the calculated value of flow resistance coefficient $\mathrm{K}$.

For the sudden expansion of the pipeline $\mathrm{K}_{\mathrm{exp}}$. (local pressure loss) will depend to the ratio of the cross sections areas of the channel of the pipeline before and after the local hydraulic resistance. $\mathrm{K}_{\text {exp. }}$ is calculated by the formula (1)

$$
\mathrm{K}_{\text {exp. }}=\left(1-\frac{\mathrm{S}_{1}}{\mathrm{~S}_{2}}\right)^{2},
$$

where $S_{1}-$ cross section area of the channel of the pipeline before the local resistance, $\mathrm{mm}^{2} ; \mathrm{S}_{2}-$ cross section area of the channel of the pipeline after the local resistance, $\mathrm{mm}^{2}$.

For the sudden contraction of the pipeline $\mathrm{K}_{\text {cont }}$. will depend to the ratio of the cross sections areas of the channel of the pipeline after and before the local hydraulic resistance. $\mathrm{K}_{\text {cont. }}$ is calculated by the formula (2)

$$
\mathrm{K}_{\text {cont. }}=0.5 \cdot\left(1-\frac{\mathrm{S}_{2}}{\mathrm{~S}_{1}}\right)^{0.75} .
$$

For the gradual expansion and contraction of

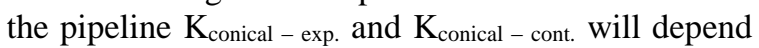
to the opening angle of the diffuser or confuser $\alpha$ (deg.). The calculation of coefficients is performed by two conditions: $\alpha<45^{\circ}$ and $\alpha>45^{\circ}$. $\mathrm{K}_{\text {conical }- \text { exp. }}$ and $\mathrm{K}_{\text {conical }}$ - cont. are calculated by the systems of equations (3) and (4) respectively

$$
\left\{\begin{array}{l}
\mathrm{K}_{\text {conical-exp. }}=2.6 \sin \left(\frac{\alpha}{2}\right)\left(1-\frac{\mathrm{S}_{1}}{\mathrm{~S}_{2}}\right)^{2} \\
\mathrm{~K}_{\text {conical-exp. }}=\left(1-\frac{\mathrm{S}_{1}}{\mathrm{~S}_{2}}\right)^{2}
\end{array},\right.
$$




\begin{tabular}{|c|c|c|c|c|c|c|}
\hline Impact Factor: & $\begin{array}{l}\text { ISRA (India) } \\
\text { ISI (Dubai, UAF } \\
\text { GIF (Australia) } \\
\text { JIF }\end{array}$ & $\begin{array}{l}=1.344 \\
=0.829 \\
=0.564 \\
=1.500\end{array}$ & $\begin{array}{l}\text { SIS (USA) } \\
\text { PИНЦ (Russia) } \\
\text { ESJI (KZ) } \\
\text { SJIF (Morocco) }\end{array}$ & $\begin{array}{l}=0.912 \\
=0.234 \\
=1.042 \\
=\mathbf{2 . 0 3 1}\end{array}$ & $\begin{array}{l}\text { ICV (Poland) } \\
\text { PIF (India) } \\
\text { IBI (India) }\end{array}$ & $\begin{array}{l}=6.630 \\
=1.940 \\
=4.260\end{array}$ \\
\hline
\end{tabular}

$$
\left\{\begin{array}{l}
\mathrm{K}_{\text {conical-cont. }}=0.8 \sin \left(\frac{\alpha}{2}\right)\left(1-\frac{\mathrm{S}_{1}}{\mathrm{~S}_{2}}\right) \\
\mathrm{K}_{\text {conical-cont. }}=0.5 \sqrt{\sin \left(\frac{\alpha}{2}\right)}\left(1-\frac{\mathrm{S}_{1}}{\mathrm{~S}_{2}}\right)
\end{array},\right.
$$

where the first equation in the systems for $\alpha<45^{\circ}$, the second - for $\alpha>45^{\circ}$.

The calculation of the local changes in the fluid pressure before and after the local hydraulic resistances will determine the total pressure loss on the length of the pipeline.

\section{Materials, methods and results}

The simulation of the fluid flow in the pipelines with the local hydraulic resistances was performed in the ElmerGUI module. The process of the fluid flow under the following local hydraulic resistances of the pipeline: the sudden expansion; the sudden contraction; the gradual expansion (diffuser); the gradual contraction (confuser) was researched.

The cross section area of the channel of the pipeline after the local hydraulic resistances (on the output) was taken at $25 \%$ more or less than the cross section area of the channel of the pipeline on the inlet. The length of the confuser and diffuser, when these ratios the cross sections areas of the channels of the pipeline on the inlet and outlet, was made $30 \mathrm{~mm}$.

Each of the solid models of the pipelines was partitioned more than on 30000 volumetric finite elements. In the sections of the local hydraulic resistances of models of the pipelines the mesh density was increased, which allowed us to obtain more accurate results of the calculation of the transient process of the fluid flow.

The simulation of the laminar fluid flow in the pipeline was performed on the basis of Navier-Stokes equations. The velocity profile of the fluid flow at the inlet of the pipeline (component $\mathrm{X}$ ) was specified by equation (5)

where $\mathrm{y} \in[1,2]$.

$$
\mathrm{v}_{\mathrm{x}}=6(\mathrm{y}-1)(2-\mathrm{y}),
$$

The properties of the fluid in steady flow: density $-1.0 \mathrm{~kg} / \mathrm{m}^{3}$ and viscosity $-0.01 \mathrm{~Pa} \cdot \mathrm{s}$ was set (the following models of viscosity are available Power law, Power law too, Carreau, Cross, Power Eyring, Thermal Carreau, Smagorinsky, K-Epsilon, RNG K-Epsilon, Spalart-Allmaras, K-Omega, SST K-Omega, Levelset). For the inside wall of the pipeline was made a condition no-slip. The maximum number of iterations for problem calculation of hydrodynamics -20 .

The initial conditions of the process of the simulation of fluid flow in pipelines with the local hydraulic resistances and the results of the calculation are presented in Fig. 1 - 4 .

The processing of simulation results and their visual display was implemented in ParaView (a cross-platform package) [7;8]. In the cross sections 1 -1 (centerline of the models), $2-2$ (radius of the channel of the pipeline before the local resistance) and $3-3$ (radius of the channel of the pipeline after the local resistance) was determined by changing of the magnitude of hydraulic fluid pressure in the channels of the pipelines. On the length of the considered channels of the pipeline fluid the pressure has positive and negative values. The dynamic pressure of the fluid in the pipeline is positive. The negative pressure values were calculated provided the fluid flow in the empty cavity of the channel of the pipeline.

At the sudden increase of the cross section of the pipeline a sharp pressure drop is occurred on a length equal to two diameters of the channel after the local resistance. The fluid pressure in the cross sections $2-2$ and $3-3$ is negative and is increased with increasing radiuses of the channels. The pressure in the cross section $3-3$ more than in the cross section $2-2$.

With the gradual expansion of the channel cross section of the pipeline the maximum dynamic pressure is acted on the output of the local resistance. The pressure in the cross section $2-2$ with increasing radius of the channel has negative and positive values. The fluid pressure after the local hydraulic resistance is obtained with negative values. Herewith on the inner wall of the pipeline the magnitude of the pressure is minimum.

The constant pressure on the channel length of the pipeline to the sudden contraction is replaced by a sharp drop after the local resistance. This is confirmed by the change of the fluid pressure in the cross sections $2-2$ (negative) and $3-3$ (positive).

On the output of the gradual contraction of the channel of the pipeline is observed a sharp jump of the negative pressure. After the local resistance, negative pressure is maintained in the channel. The pressure in the cross section $2-2$ is changed similarly by the fluid pressure before the gradual expansion of the pipeline.

The lines of fluid flow in the channels of the pipelines with the local hydraulic resistances were obtained by interpolator with point locator. The integration was performed by the fourth-order Runge-Kutta method [9] when setting the following parameters: integration step unit - cell length, initial step length -0.2 , minimum step length -0.01 , maximum step length -0.5 . A maximum streamline length of the flow was adopted value of 100 . The terminal speed of the calculation was adopted value of $1 \cdot 10^{-12}$, with a maximum error to $1 \cdot 10^{-6}$. The interpolation of the intensity of lighting of the results of calculation was performed by Gouraud method [10]. 


\begin{tabular}{l|lrl|l|ll} 
& ISRA (India) & $=\mathbf{1 . 3 4 4}$ & SIS (USA) & $=\mathbf{0 . 9 1 2}$ & ICV (Poland) & $=\mathbf{6 . 6 3 0}$ \\
Impact Factor: & ISI (Dubai, UAE) $=\mathbf{0 . 8 2 9}$ & PUHU (Russia) $=\mathbf{0 . 2 3 4}$ & PIF (India) & $=\mathbf{1 . 9 4 0}$ \\
& GIF (Australia) & $\mathbf{0 . 5 6 4}$ & ESJI (KZ) & $=\mathbf{1 . 0 4 2}$ & IBI (India) & $\mathbf{4 . 2 6 0}$
\end{tabular}

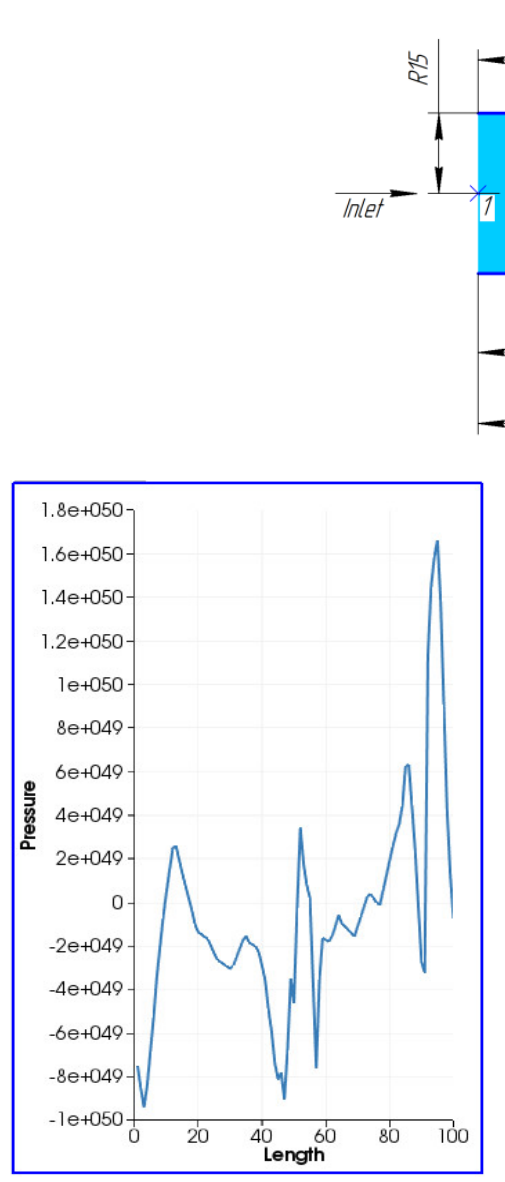

b)

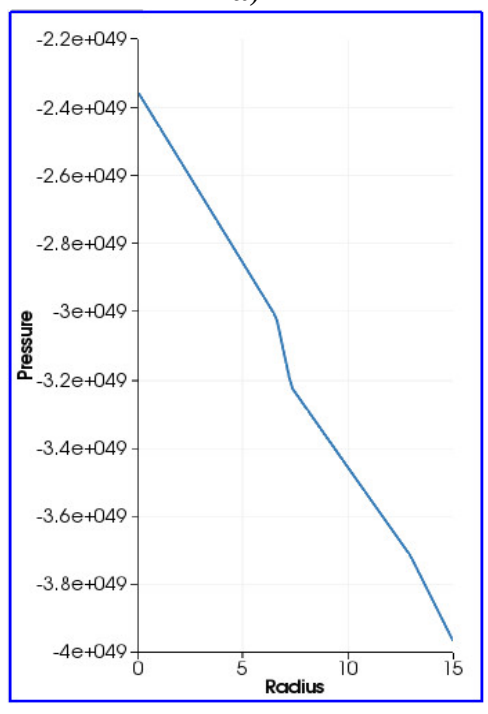

c)

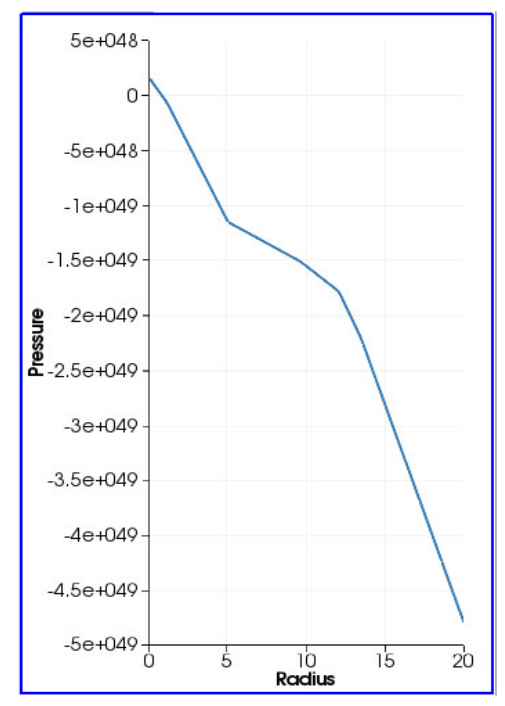

d)

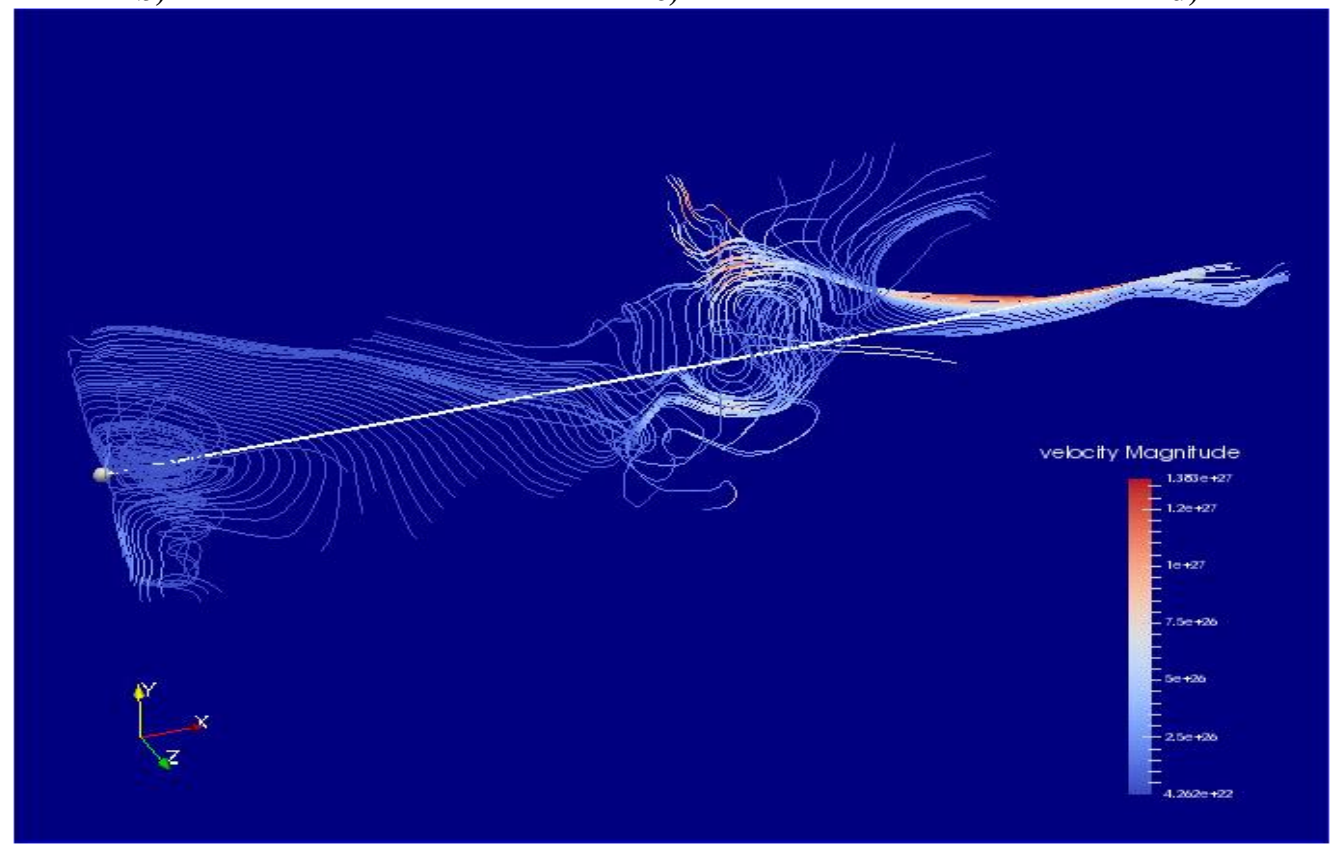

e)

Figure 1 - The simulation of the fluid flow when the sudden expansion channel of the pipeline: $\mathbf{a}-\mathbf{a}$ schematic representation of the simulated problem; $b$ - the dependence of the change of fluid pressure on the total length of the pipeline (longitudinal section $1-1$, centerline of the pipeline); $\mathrm{c}$ - the dependence of fluid pressure when the changing the radius of channel of the pipeline from centerline to the inner wall (cross section 2-2, before the sudden expansion); $d$ - the dependence of fluid pressure when the changing the radius of channel of the pipeline from centerline to the inner wall (cross section $3-3$, after the sudden expansion); $\mathrm{e}$ - the direction and velocity of the fluid flow in the channel of the pipeline.

ISPC Generalization of scientific results,

Scranton, USA 


\begin{tabular}{l|lrl|l|ll} 
& ISRA (India) & $=\mathbf{1 . 3 4 4}$ & SIS (USA) & $=\mathbf{0 . 9 1 2}$ & ICV (Poland) & $=\mathbf{6 . 6 3 0}$ \\
Impact Factor: & ISI (Dubai, UAE) $=\mathbf{0 . 8 2 9}$ & PUHU (Russia) $=\mathbf{0 . 2 3 4}$ & PIF (India) & $=\mathbf{1 . 9 4 0}$ \\
& GIF (Australia) & $\mathbf{0 . 5 6 4}$ & ESJI (KZ) & $=\mathbf{1 . 0 4 2}$ & IBI (India) & $\mathbf{4 . 2 6 0}$
\end{tabular}

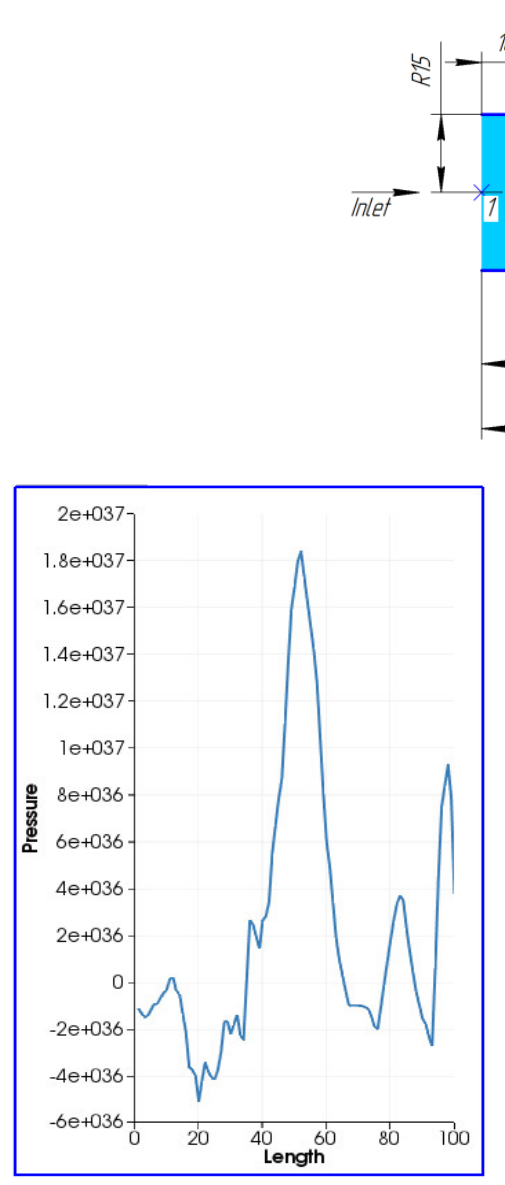

b)

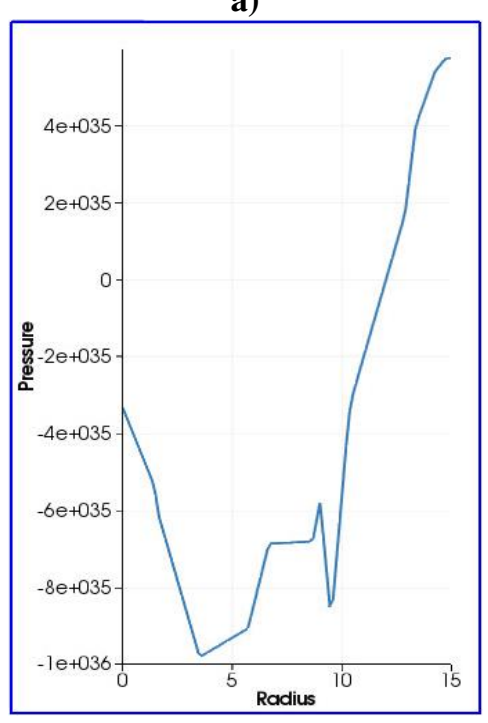

c)
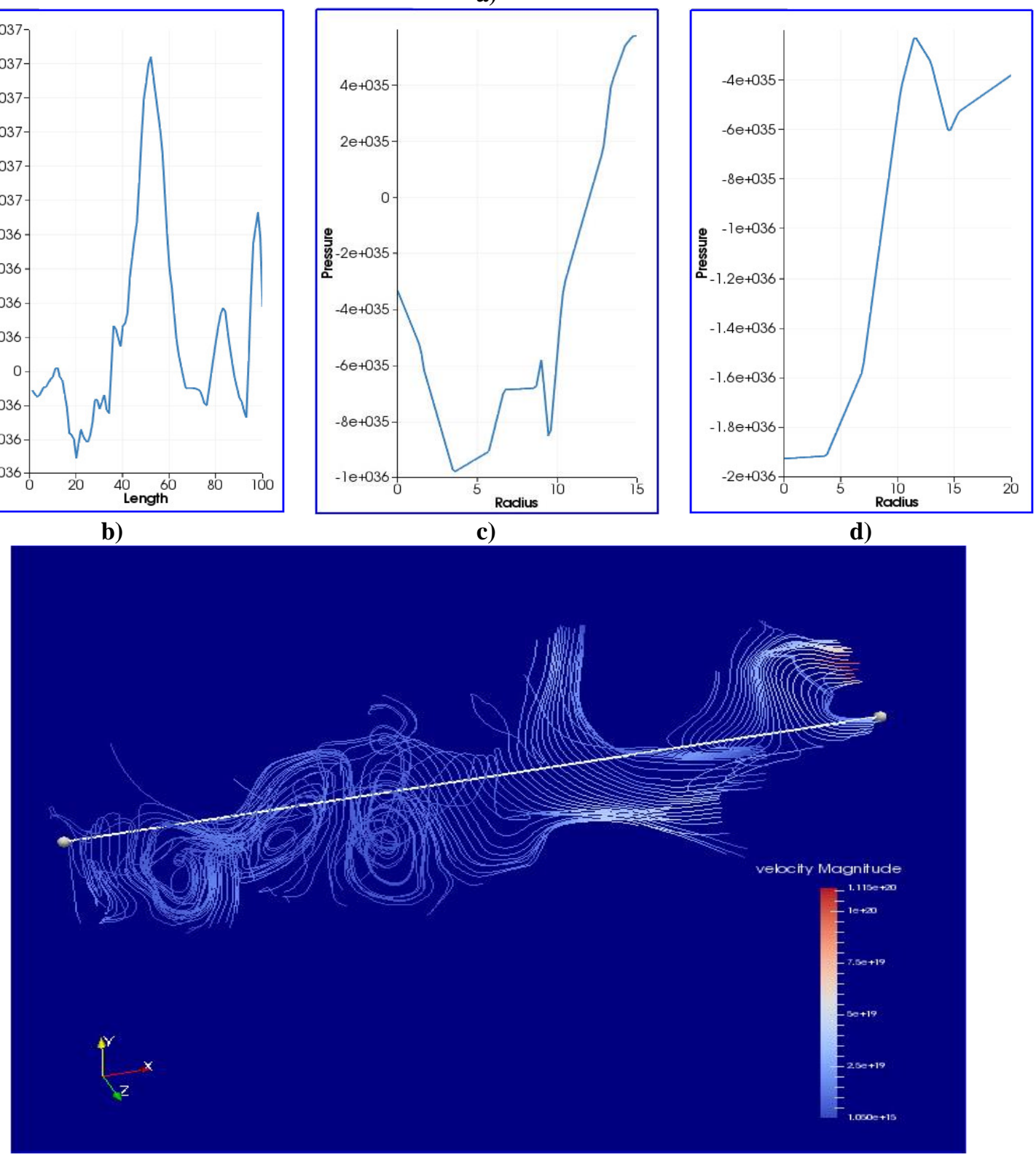

e)

Figure 2 - The simulation of the fluid flow when the gradual expansion channel of the pipeline (diffuser): a a schematic representation of the simulated problem; $b$ - the dependence of the change of fluid pressure on the total length of the pipeline (longitudinal section $1-1$, centerline of the pipeline); $c$ - the dependence of

fluid pressure when the changing the radius of channel of the pipeline from centerline to the inner wall (cross section $2-2$, before the diffuser); $d$ - the dependence of fluid pressure when the changing the radius of channel of the pipeline from centerline to the inner wall (cross section $3-3$, after the diffuser); $e-$ the direction and velocity of the fluid flow in the channel of the pipeline.

ISPC Generalization of scientific results, 


\begin{tabular}{l|lrl|l|ll} 
& ISRA (India) & $=\mathbf{1 . 3 4 4}$ & SIS (USA) & $=\mathbf{0 . 9 1 2}$ & ICV (Poland) & $=\mathbf{6 . 6 3 0}$ \\
Impact Factor: & ISI (Dubai, UAE) $=\mathbf{0 . 8 2 9}$ & PUHU (Russia) $=\mathbf{0 . 2 3 4}$ & PIF (India) & $=\mathbf{1 . 9 4 0}$ \\
& GIF (Australia) & $\mathbf{0 . 5 6 4}$ & ESJI (KZ) & $=\mathbf{1 . 0 4 2}$ & IBI (India) & $\mathbf{4 . 2 6 0}$
\end{tabular}

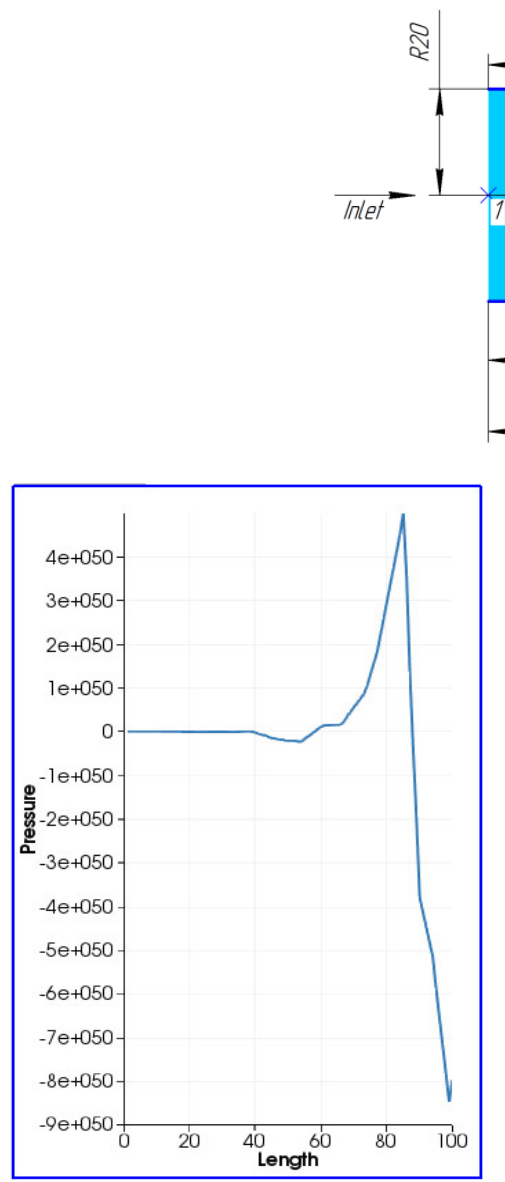

b)

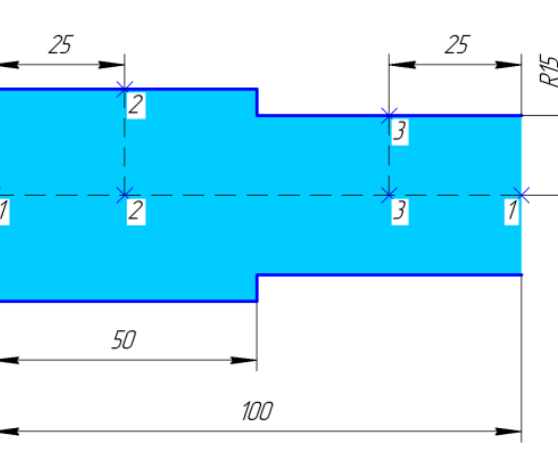

a)

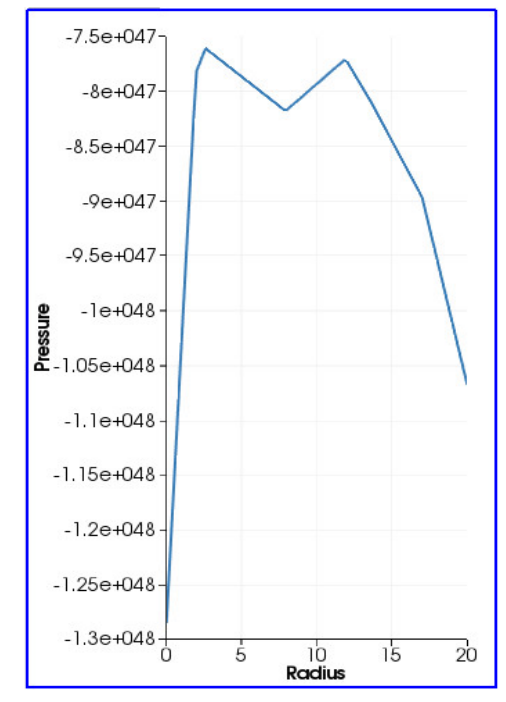

c)

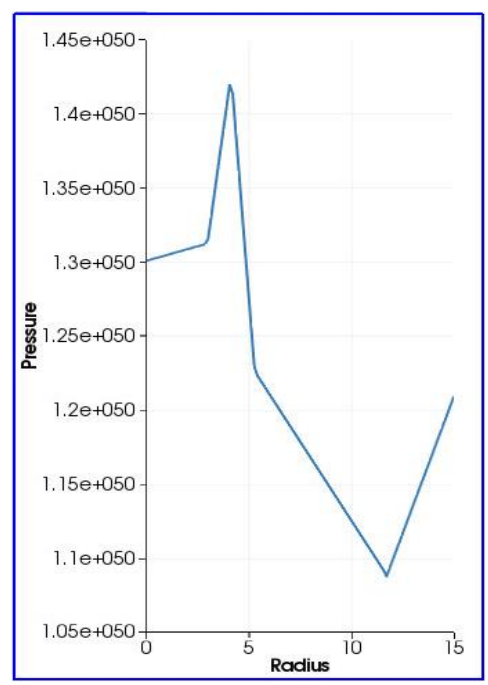

d)

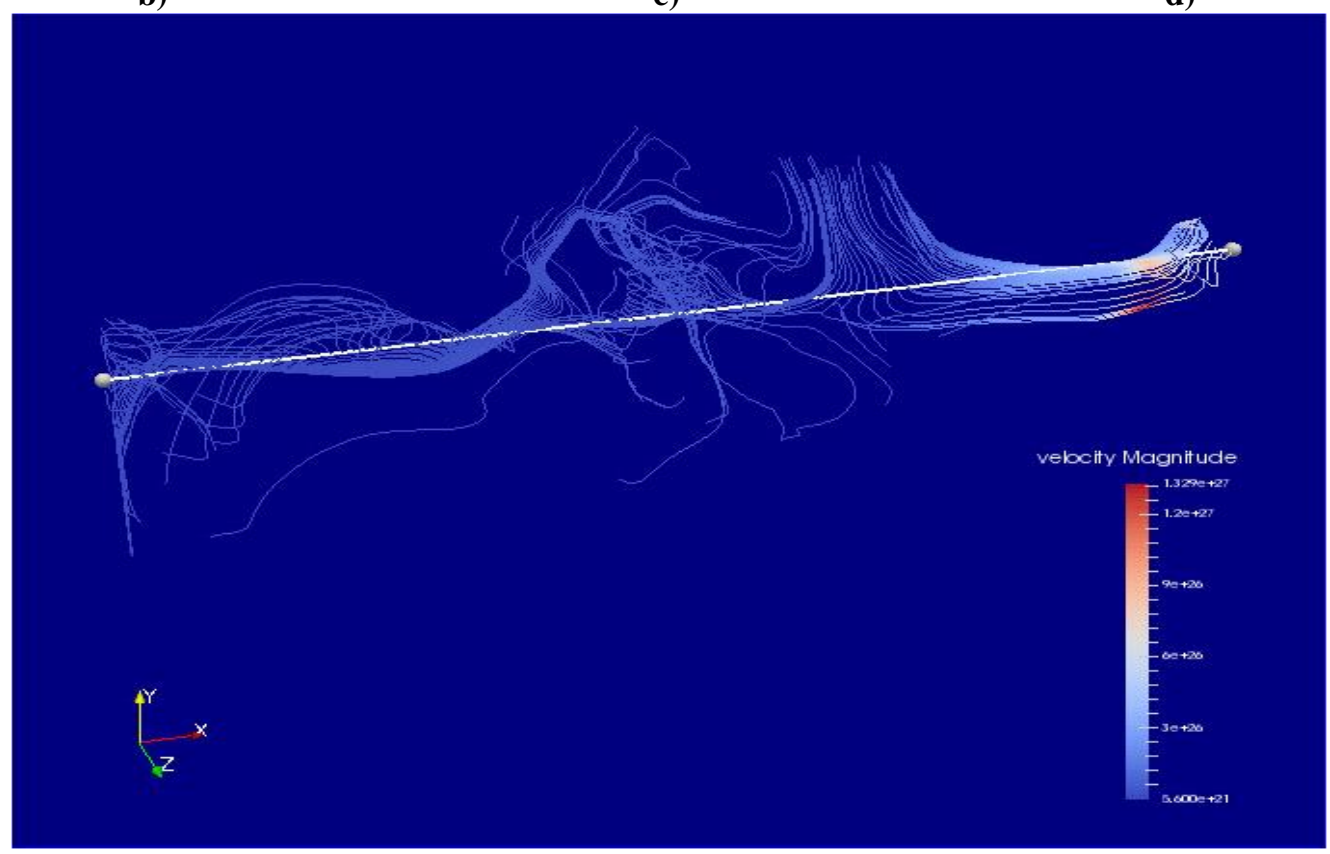

e)

Figure 3 - The simulation of the fluid flow when the sudden contraction channel of the pipeline: $\mathbf{a}-\mathbf{a}$ schematic representation of the simulated problem; $b$ - the dependence of the change of fluid pressure on the total length of the pipeline (longitudinal section $1-1$, centerline of the pipeline); $c$ - the dependence of fluid pressure when the changing the radius of channel of the pipeline from centerline to the inner wall (cross section $2-2$, before the sudden contraction); $d$ - the dependence of fluid pressure when the changing the radius of channel of the pipeline from centerline to the inner wall (cross section $3-3$, after the sudden contraction); $\mathrm{e}$ - the direction and velocity of the fluid flow in the channel of the pipeline.

ISPC Generalization of scientific results, 


\begin{tabular}{l|lrl|l|ll} 
& ISRA (India) & $=\mathbf{1 . 3 4 4}$ & SIS (USA) & $=\mathbf{0 . 9 1 2}$ & ICV (Poland) & $=\mathbf{6 . 6 3 0}$ \\
Impact Factor: & ISI (Dubai, UAE) $=\mathbf{0 . 8 2 9}$ & PUHU (Russia) $=\mathbf{0 . 2 3 4}$ & PIF (India) & $=\mathbf{1 . 9 4 0}$ \\
& GIF (Australia) & $\mathbf{0 . 5 6 4}$ & ESJI (KZ) & $=\mathbf{1 . 0 4 2}$ & IBI (India) & $\mathbf{4 . 2 6 0}$
\end{tabular}

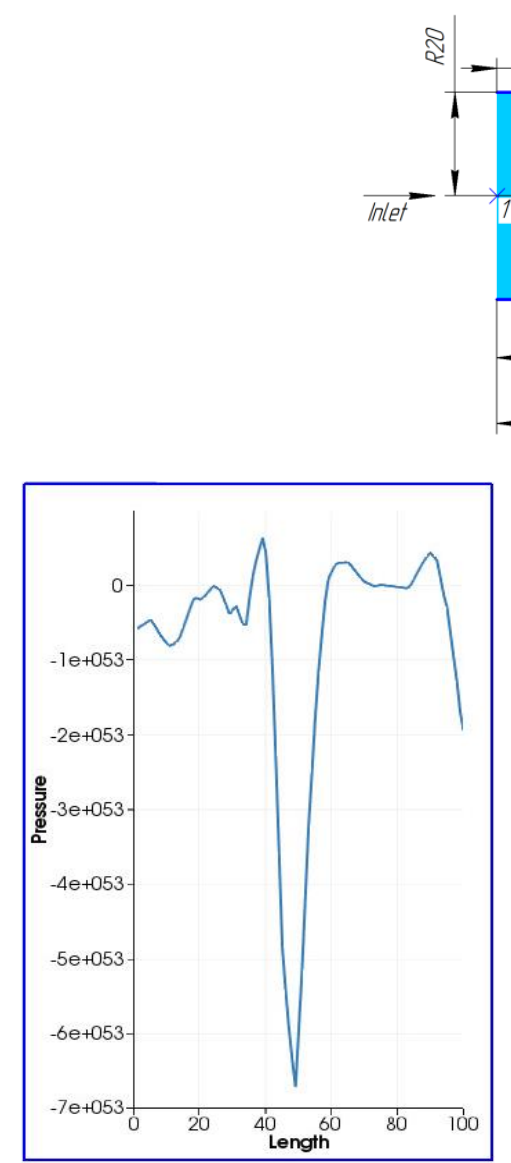

b)

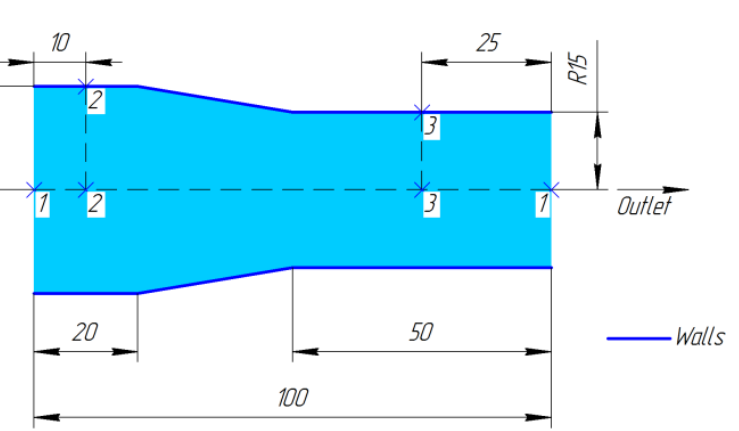

a)

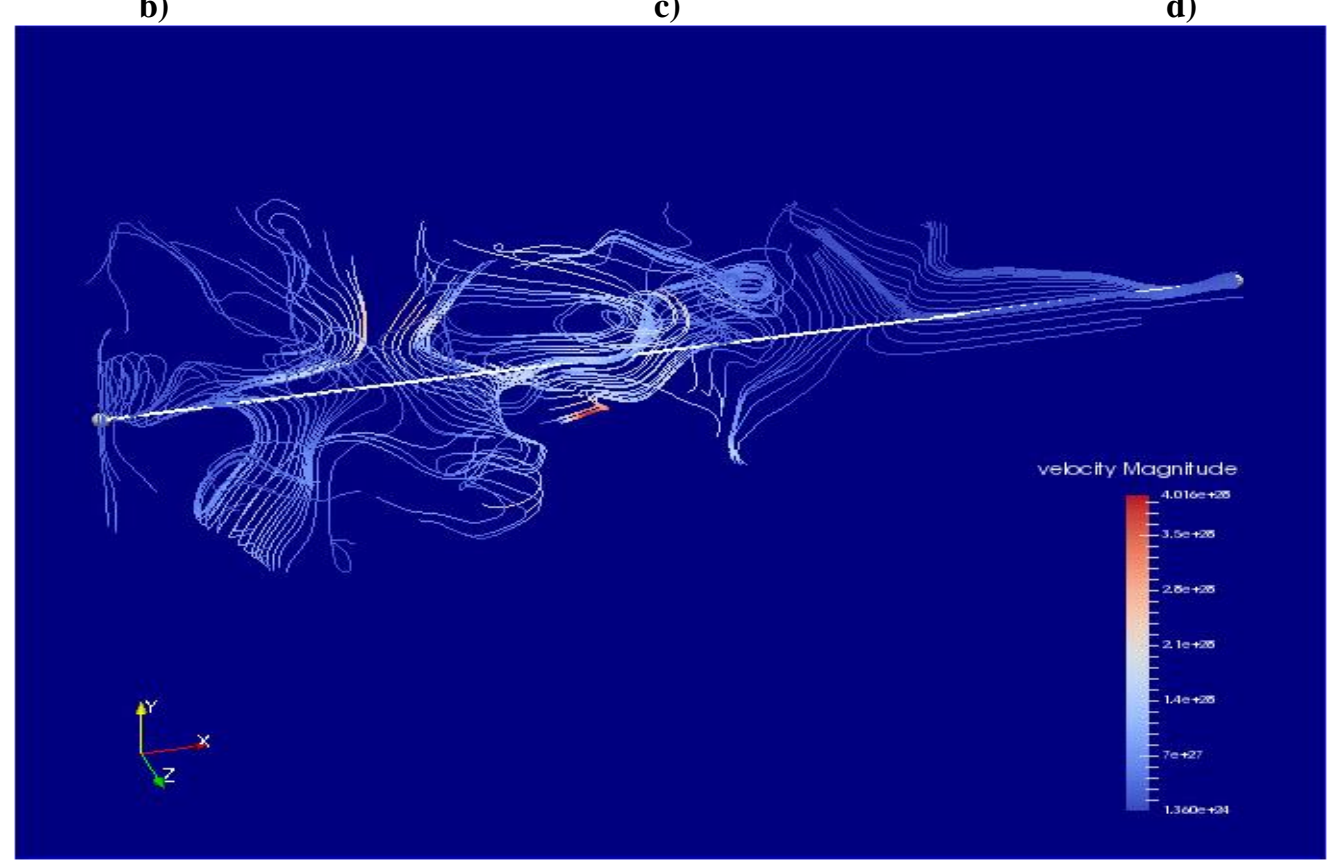

e)

Figure 4 - The simulation of the fluid flow when the gradual contraction channel of the pipeline (confuser): a - a schematic representation of the simulated problem; $b$ - the dependence of the change of fluid pressure on the total length of the pipeline (longitudinal section $1-1$, centerline of the pipeline); $c$ - the dependence of fluid pressure when the changing the radius of channel of the pipeline from centerline to the inner wall (cross section $2-2$, before the confuser); $d$ - the dependence of fluid pressure when the changing the radius of channel of the pipeline from centerline to the inner wall (cross section $3-3$, after the confuser); $e-$ the direction and velocity of the fluid flow in the channel of the pipeline.

ISPC Generalization of scientific results, 


\begin{tabular}{|c|c|c|c|c|c|c|}
\hline Impact Factor: & $\begin{array}{l}\text { ISRA (India) } \\
\text { ISI (Dubai, UAE } \\
\text { GIF (Australia) } \\
\text { JIF }\end{array}$ & $\begin{array}{l}=1.344 \\
=0.829 \\
=0.564 \\
=1.500\end{array}$ & $\begin{array}{l}\text { SIS (USA) } \\
\text { PИНЦ (Russia) } \\
\text { ESJI (KZ) } \\
\text { SJIF (Morocco) }\end{array}$ & $\begin{array}{l}=0.912 \\
=0.234 \\
=1.042 \\
=2.031\end{array}$ & $\begin{array}{l}\text { ICV (Poland) } \\
\text { PIF (India) } \\
\text { IBI (India) }\end{array}$ & $\begin{array}{l}=6.630 \\
=1.940 \\
=4.260\end{array}$ \\
\hline
\end{tabular}

The flow regime in the pipelines is turbulent. The intense vortex flows in the channel of the pipeline after the local hydraulic resistances are observed. The average velocity of fluid flow is increased on the order and remains virtually constant after the sudden expansion of the channel of the pipeline. The velocity change of the fluid flow at the sudden contraction, gradual expansion and contraction of the pipeline is occurred on small channel length after the local hydraulic resistances.

The maximum velocity of the fluid flow is noted in the condition of the gradual contraction of the channel of the pipeline, the minimum velocity at the gradual expansion of the channel of the pipeline.

\section{Conclusion}

Thus, on the basis of the results of the calculation of the fluid flow in the pipelines with the local hydraulic resistances we can do the following conclusions:

1. On the length of the pipelines with the sudden and gradual expansion of the channels is acted mainly positive pressure, after the sudden and gradual contraction of the channel of the pipeline negative pressure.

2. The pressure drop in the pipelines with the sudden change of the cross section of the channel is occurred on the length of the two internal diameters of the pipe after the resistance, with the gradual change of the cross section of the channel of the pipeline - at the outlet of the conical section.

3. The highest value of the fluid pressure was defined in the pipeline with the gradual contraction of the cross section of the channel.

\section{References:}

1. (2016) Diffuser (Aerohydrodynamics). Available:

https://ru.wikipedia.org/wiki/Диффузор (гидр оаэродинамика) (Accessed: 19.12.2016).

2. Chemezov DA, Tyurina SI, Bayakina AV, Goremykin VV (2014) Fluid transients flow in piping elbow. ISJ Theoretical \& Applied $\begin{array}{llll}\text { Science } & 12 & \text { (20): } & 4-8 .\end{array}$ http://dx.doi.org/10.15863/TAS.2014.12.20.2

3. Chemezov DA (2014) Hydrodynamic characteristics of water flow in straight and curved sections of the pipeline. 4 international scientific-practical conference «Modern materials, equipment and technology», December 25-26, Kursk. - p. 468-471.

4. Chemezov DA, Kukhar NA, Kovalenko NO (2015) Fluid flow in steel tubular coil (distribution of pressure gradient). Collection of scientific works XII $^{\text {th }}$ International scientificpractical conference «Modern tool systems, information technologies and innovations», March 19-20, Kursk. - p. 243-247.

5. Chemezov DA, Bayakina AV (2014) Simulation modeling of water flow in the
Venturi nozzle. ISJ Theoretical \& Applied Science 07 (15): 25-29. doi: http://dx.doi.org/10.15863/TAS.2014.07.15.4

6. Voitovich LN, Emelianova GN (1985) Experimental and theoretical research of hydraulic resistance of a conical diffuser with a rough surface. TsAGI Science Journal, № 4, vol. XVI. - p. 105-110.

7. (2016) ParaView. Available: https://en.wikipedia.org/wiki/ParaView

(Accessed: 19.12.2016).

8. Ayachit U, Bauer A, Chaudhary A, DeMarle D, Geveci B, Jourdain S, Lutz K, Marion P, Maynard R, Shetty N, Yuan Y, Zagaris G, Scott A, Moreland K, Brandon M. ParaView Manual. Version 4.0. A parallel visualization application.

9. (2016) Runge-Kutta methods. Available: https://en.wikipedia.org/wiki/RungeKutta methods (Accessed: 19.12.2016).

10. (2016) Gouraud shading. Available: https://en.wikipedia.org/wiki/Gouraud_shading (Accessed: 19.12.2016). 